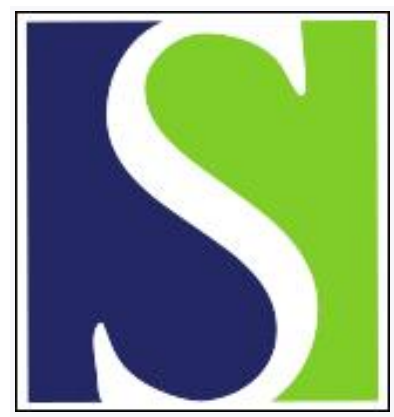

Scand J Work Environ Health 2016;42(6):469-480

https://doi.org/10.5271/sjweh.3588

Published online: 29 Aug 2016, Issue date: 01 Jun 2016

Effectiveness of a return-to-work program for workers without an employment contract, sick-listed due to common mental disorders

by Lammerts L, Schaafsma FG, Bonefaas-Groenewoud K, van Mechelen W, Anema JR

A participatory supportive return-to-work (RTW) program did not result in a significant shorter duration until sustainable RTW of workers without an employment contract, sick-listed due to a common mental disorder, compared to usual occupational healthcare. Further research is needed to consider how vocational needs of these vulnerable workers could be better addressed.

Affiliation: Department of Public and Occupational Health, EMGO+ Institute for Health and Care Research, VU University Medical Center, Van der Boechorststraat 7, NL-1081 BT Amsterdam, The Netherlands. f.schaafsma@vumc.nl

Refers to the following texts of the Journal: 2010;36(6):488-498 2011;37(3):186-195 2013;39(2):144-154 2014;40(4):343-352

The following article refers to this text: 2022;48(5):361-371

Key terms: common mental disorder; employment contract; mental disorder; occupational healthcare; randomized controlled trial; RCT; return to work; return-to-work; RTW; sick leave; sickness absence; sickness absence; temporary employment; temporary worker; unemployment; vulnerable worker

This article in PubMed: www.ncbi.nlm.nih.gov/pubmed/27571387

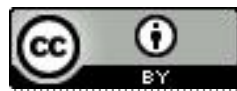




\title{
Effectiveness of a return-to-work program for workers without an employment contract, sick-listed due to common mental disorders
}

\author{
by Lieke Lammerts, MSc, ${ }^{1,2}$ Frederieke G Schaafsma, MD, PhD, ${ }^{1,2}$ Karin Bonefaas-Groenewoud, MSc, ${ }^{1,2}$ \\ Willem van Mechelen, MD, PhD, ${ }^{1}$ Johannes R Anema, MD, PhD ${ }^{1,2}$
}

\begin{abstract}
Lammerts L, Schaafsma FG, Bonefaas-Groenewoud K, van Mechelen W, Anema JR. Effectiveness of a return-towork program for workers without an employment contract, sick-listed due to common mental disorders. Scand J Work Environ Health. 2016;42(6):469-480. doi:10.5271/sjweh.3588
\end{abstract}

\begin{abstract}
Objectives Both the presence of mental health problems and the absence of an employment contract have been related to long-term sickness absence and unemployment, indicating a need for return-to-work (RTW) interventions. Our aim was to study the effectiveness of a new participatory, supportive RTW program for workers without an employment contract, sick-listed 2-14 weeks due to a common mental disorder, in comparison with usual care.

Methods A participatory approach, integrated care and direct placement in a competitive job were part of the new program. The primary outcome measure was duration until first sustainable RTW in competitive employment. Cox regression analysis was applied to study this outcome. Secondary outcome measures were average working hours, duration until any type of employment, sickness benefit duration, and perceived health and functioning.

Results In total, 186 participants were included in the study and randomly allocated to an intervention group $(\mathrm{N}=94)$, or control group $(\mathrm{N}=92)$. A hazard ratio (HR) of 1.15 (95\% CI 0.61-2.16) for duration until first sustainable RTW indicated no significant effect of allocation to the new program, compared to usual care. Furthermore, no significant differences were found in favor of the intervention group on any secondary outcome.

Conclusions Compared to usual care, the new program did not result in a significant shorter duration until first sustainable RTW. However, due to low protocol adherence, it remains unclear what the results would have been if the program had been executed according to protocol.
\end{abstract}

Key terms occupational healthcare; randomized controlled trial; RCT; RTW; sick leave; sickness absence; temporary employment; temporary worker; unemployment; vulnerable worker.

Mental health problems are prevalent in the working-age population of many developed countries (1). Important consequences are high rates of sickness absence and unemployment, resulting in enormous societal costs (1) and individual suffering $(2,3)$. Common mental health problems are mild-to-moderate depressive, anxiety, and stress-related complaints, which have also been described as common mental disorders (CMD) (1). The large impact of CMD on society has led to a growing attention in recent literature for the development and evaluation of interventions that aim to promote returnto-work (RTW) of workers on sick leave due to a CMD (4-14). Many of these studies focused on sick-listed employees, ie, workers with an employment contract.
Up to now, little attention has been paid to the development and evaluation of RTW interventions for sicklisted workers without an employment contract, such as temporary agency workers, those with an expired fixed-term contract, and unemployed workers (15). This is an important concern as these workers seem to have a more vulnerable position in the labor market. Compared to sick-listed employees, they appear to be at risk of longer disability episodes $(16,17)$. Moreover, in the last decennia, flexible forms of employment - such as temporary employment - have globally expanded $(18,19)$.

In the Netherlands, sick-listed workers without an employment contract are entitled to sickness benefit payment and occupational healthcare $(\mathrm{OHC})$ by the

1 Department of Public and Occupational Health, EMGO+ Institute for Health and Care Research, VU University Medical Center, Amsterdam, The Netherlands.

2 Research Center for Insurance Medicine AMC-UMCG-UWV-VUmc, Amsterdam, The Netherlands.

Correspondence to: Frederieke G Schaafsma, Department of Public and Occupational Health, EMGO+ Institute for Health and Care Research, VU University Medical Center, Van der Boechorststraat 7, NL-1081 BT Amsterdam, The Netherlands. [E-mail: f.schaafsma@vumc.nl] 
Dutch Social Security Agency (SSA). Within this group, mental health problems are the most common reason for sick-listing $(20,21)$. Often these workers experience several (psychosocial) RTW barriers and have a negative perception of their health condition (22). In many cases, the absence of a workplace to return to is the main RTW obstacle (23).

A participatory, supportive RTW program was developed to promote RTW of workers who filed a sickness benefit claim at the Dutch SSA due to a CMD. The program was based on an existing participatory approach, which had previously shown promising results among a similar group of workers sick-listed due to musculoskeletal disorders (24). Direct placement in a competitive job by a vocational rehabilitation agency was added to the program to overcome the main RTW obstacle, ie, the absence of a workplace. Moreover, through application of an integrated care approach, collaboration between OHC professionals of the Dutch SSA and (mental) healthcare providers was stimulated within this new program.

In this study, we present the effects of the participatory, supportive RTW program. The main aim of this study was to evaluate the program's effectiveness in reducing the duration until first sustainable RTW in competitive employment, compared to usual $\mathrm{OHC}$ by the Dutch SSA. Secondary outcome measures were average working hours, duration until RTW in any type of employment, sickness benefit duration, and perceived physical and mental health and functioning.

\section{Methods}

\section{Study design and setting}

The study design consisted of a randomized controlled trial (RCT) with two arms - an intervention and control group - and a follow-up period of 12 months. Entitled the "Co-WORK study", this trial was conducted in collaboration with seven offices of the Dutch SSA, located in three districts, and three vocational rehabilitation agencies. The Medical Ethics Committee of the VU University Medical Center approved the study design and all participants signed informed consent. The trial was registered at the Dutch Trial Register (Nederlands Trial Register) (NTR3563).

\section{Study population and recruitment}

Sick-listed workers (18-64 years), who applied for a sickness benefit at the Dutch SSA due to the (partial) absence of an employment contract and belonged to one of the participating SSA offices, received an invitational letter together with a short questionnaire 1-2 weeks after being sick-listed. Because during recruitment it was no longer possible to recruit on the basis of a registered mental health complaint, every newly sick-listed worker received an invitation and was asked to indicate whether he/she was sick-listed due to mental health problems. Furthermore, the short questionnaire consisted of a screener for distress (25), questions about the intention to return to work despite ongoing health complaints, and about the date of sick-listing. The RTW intention was measured on a 5-point Likert scale with responses: "certainly not", "probably not", "maybe", "probably", and "certainly". Sick-listed workers could only participate if they experienced an elevated level of distress and were sick-listed for $\leq 14$ weeks. Exclusion criteria included: (i) not being able to complete questionnaires written in the Dutch language; (ii) having a conflict with the SSA regarding a sickness benefit claim or a long-term disability claim; (iii) the presence of a legal conflict, eg, an ongoing injury compensation claim; (iv) a sickness absence episode due to a CMD within one month before the current sickness benefit claim; (v) already having received usual $\mathrm{OHC}$ since the start of the current sickness absence period; (vi) pregnancy, up until three months after delivery; (vii) no signed informed consent form; and (viii) probably/ certainly not having the intention to return to work despite ongoing health complaints. This latter criterion was based on findings of two earlier studies $(12,24)$, which showed that sick-listed workers without this positive RTW intention require another type of intervention (12). Sick-listed workers who were willing to participate and met the criteria for eligibility, were contacted by the researcher by telephone to screen for other in- and exclusion criteria.

After randomization, intervention group participants could still be excluded from participation in the RTW program in case their insurance physician assessed a (medical) contraindication for participation. However, these individuals remained in the intervention group, based on the intention-to-treat principle.

\section{Randomization and blinding}

Randomization was performed at participant level. To ensure an equal distribution, prestratification was applied to different types of workers (before sick-listing) - ie, unemployed, temporary agency, and fixed-term contract worker - and the three participating SSA districts. A block randomization table with a fixed block size of four was generated for each stratum, based on schemes with random permuted numbers. Randomization was performed by a research assistant during an intake meeting with the participant.

Blinding participants and professionals for the randomization result was not possible due to the nature of the intervention. To minimize bias caused by self-report, 
we collected registered data from the SSA when possible. A research assistant entered all data into a database using a unique research number for each participant to guarantee blinded analyses by the researcher.

\section{Interventions}

Dutch SSA usual care. The Dutch SSA provides OHC in a team of professionals, consisting of a RTW coordinator, an insurance physician and a labor expert. The RTW coordinator investigates why the sick-listed worker thinks that he/she is unable to work. He/she monitors the full vocational rehabilitation process and refers the worker to the insurance physician or labor expert if necessary. The insurance physician is encouraged to follow the guidelines for OHC of the Dutch Society of Occupational Medicine. He/she advises the sick-listed worker about recovery and RTW based on a medical problem analysis. If necessary, he/she refers to further treatment options to prevent work disability. The labor expert provides vocational rehabilitation support and advises the sick-listed worker about RTW options, using his/ her expertise of the labor market. He/she can decide to refer the sick-listed worker for additional support, such as assistance from a vocational rehabilitation agency.

The RTW program. Participants of both groups received usual OHC from the SSA. However, participants in the intervention group were referred to a more standardized form of $\mathrm{OHC}$ that started early after sick-listing, ie, the participatory supportive RTW program.

Within two weeks after allocation of the participant to the program, the RTW coordinator conducts an analysis followed by a medical problem analysis by the insurance physician. Subsequently, the latter contacts the participant's healthcare provider(s) to agree on treatment and RTW. The RTW coordinator encourages the participant to play an active role in his/her own vocational rehabilitation process and to list all RTW obstacles. This list is then used as a starting point for a meeting between the worker and the labor expert, in which all obstacles are jointly prioritized. Also the RTW coordinator, with help from the labor expert, makes a list of RTW obstacles facing this particular worker. Subsequently, in the following two weeks, the participant has another meeting with both the RTW coordinator and the labor expert, during which they jointly search for solutions to overcome the prioritized obstacles and discuss suitable work. When consensus is reached, solutions and suggestions to find suitable work are summarized in a RTW action plan. During the making of this action plan, the participant's responsibility in implementing the action plan is emphasized. To facilitate the job search, the participant is referred to a vocational rehabilitation agency. Within another four weeks, this agency offers the participant $\geq 2$ competitive jobs with a minimum contract period of three months, matching with the RTW action plan. The RTW coordinator monitors the process and refers the participant to another vocational rehabilitation agency for additional support if necessary.

More information about the study design and setting, procedures used for recruitment, randomization and blinding, the sample size calculation, and the participatory, supportive RTW program can be found in the study protocol (26).

\section{Assessment of protocol adherence and contamination}

We used findings of our previous process evaluation to assess the number of intervention group participants that participated in each step of the program. These findings have been described in more detail elsewhere (27). For all participants, we assessed both registered information about consultations with SSA professionals and self-reported information about additional vocational rehabilitation support or medical cointerventions.

\section{Outcome measures and data collection}

Data regarding paid employment, sickness absence, and type of worker were collected from the SSA database. Additional data on RTW and sickness absence were assessed every three months using questionnaires. Other outcomes were measured every six months. Possible confounders were measured at baseline, after informed consent was signed and prior to randomization.

\section{Primary outcome measure}

The primary outcome was the duration in calendar days from the day of enrollment in the study until first paid employment in a regular work-setting for $\geq 28$ consecutive calendar days. It was possible that the participant was still partially at work at the time of enrollment in the study. In that case, the participant was considered to have reached the outcome if he/she had returned to work for the hours for which he/she had been sick-listed. Our RTW assessment was not restricted to full work resumption. The first and third authors assessed this outcome while the second author checked this interpretation on inconsistencies in ten random cases.

\section{Secondary outcome measures}

To assess the average working hours per week, we divided the total working hours by the total number of weeks in competitive employment during follow-up.

To measure the duration until first employment in any type of work, both RTW in paid and unpaid labor were included, regardless of the duration of the work resumption. 
In line with Vermeulen et al (24), the sickness benefit period was defined as the duration between the day of enrollment in the study until ending of this benefit for $\geq 28$ days.

The Four-Dimensional Symptom Questionnaire (4DSQ) (28) and the Dutch translation of the 36-item Short Form Health Survey (SF-36) (29) were used to assess perceived mental and physical health and functioning. The 4DSQ consists of four scales measuring perceived symptoms of distress, anxiety, depression and somatization (28). The SF-36 consists of eight scales: physical functioning, role limitations due to physical health, bodily pain, general health, vitality, social functioning, role limitations due to emotional problems, and mental health. These scales were used to construct two summary component scores (physical and mental) for our population relative to standard scores, with a standard mean of $50(29,30)$.

\section{Possible confounders}

Earlier studies found associations between RTW or sickness absence duration of sick-listed workers with mental health problems and their age $(16,31,32)$, type of worker $(16,32)$, RTW expectations (31), and RTW intention (12, 24). Therefore, information was gathered about these possible confounders. We also assessed other demographic characteristics, ie, gender and education. To assess type of worker, we examined type of worker before sick-listing, the presence of an employment contract at baseline, the work schedule in the participant's last job, the average number of working hours a week, and the years worked in this kind of employment.

The participant's expectations of being able to fully return to work in the next six months were assessed on a 5-point Likert response scale and dichotomized into "very sure/sure" or "not sure nor unsure/unsure/very unsure".

RTW intention and underlying behavioral determinants, ie, Attitude, experienced Social influence and self-Efficacy regarding RTW (ASE), were assessed with a questionnaire developed earlier by Van Oostrom et al $(12,33)$. The same item used earlier in the screening questionnaire was used again to assess the RTW intention despite ongoing health complaints. In addition, the relation between health complaints and work resumption was assessed with the fear avoidance beliefs subscale of the Dutch Work Reintegration Questionnaire (WRQ) $(34,35)$.

\section{Statistical analyses}

When multiple-scale questionnaires were used, first sum scores were computed for each scale. In case of missing items, the average score of the items in the same scale were imputed for the missing items, but only in cases where at least half of the items in this scale were valid.
Descriptive statistics were used to compare baseline characteristics of the intervention and control groups. T-tests for continues variables and Pearson Chi-Square tests for categorical variables were performed to assess the statistical significance of possible differences between groups.

Techniques originating from survival analysis were used to analyze the effects of allocation to the intervention or control group on duration until first sustainable RTW in a competitive job, duration until RTW in any type of work, and the sickness benefit duration. Kaplan Meier curves were plotted to describe the duration until these outcomes in both groups. When no median duration could be assessed because $<50 \%$ of the participants eventually reached the outcome, we instead assessed the duration until the outcome was reached by $\geq 25 \%$ of the participants. Subsequently, Cox regression analysis was used to estimate the hazard ratio's (HR) for these outcomes and corresponding 95\% confidence intervals (CI). In case the proportion between the Kaplan Meier curves seemed to change over time, we investigated whether the HR were significantly different for different time periods by adding an interaction term between group and a time dependent covariate to the model.

Linear regression analyses were applied to investigate differences between the two groups in the average working hours per week.

Linear mixed models were used to investigate the longitudinal effect on perceived mental and physical health and functioning. The models were adjusted for differences in outcomes at baseline. To adjust for the dependency of multiple measurements in time within the same participant, a random intercept was included. We also accounted for possible clustering at the level of participating SSA offices. Random coefficients were added to the model at this level in case the difference between the results of the $-2 \log$ (restricted) likelihood tests of the new and previous model differed at least 3.84 points, after adding a random intercept, and 5.99 points, after adding a random slope.

All analyses were adjusted block-wise for possible confounding factors. The analyses were applied according to the intention-to-treat principle. In addition, perprotocol analyses were performed. For all analyses a P-value of $<0.05$ (two-tailed) was considered statistically significant. The analyses were performed in SPSS 22 (IBM, Armonk, NY, USA).

\section{Results}

\section{Participant flow}

The flow of sick-listed workers in the Co-WORK study is illustrated in figure 1. Between March 2013 and Sep- 
tember 2014, 9822 sick-listed workers were approached for participation in the study. In total, 186 participants were included in the study and randomly allocated to an intervention $(\mathrm{N}=94)$ or control $(\mathrm{N}=92)$ group.

\section{Loss to follow-up}

Data about paid employment, sickness absence, type of worker, and SSA consultations could be collected from the SSA database for all participants $(100 \%)$. Availability of self-reported data within each group is illustrated in figure 1.

\section{Baseline characteristics}

Table 1 presents the baseline characteristics of participants in both groups. There were mainly small, non-significant differences between the groups, except for the expectation regarding RTW within six months $(\mathrm{P}<0.01)$.

\section{Occupational healthcare}

Figure 1 illustrates the $\mathrm{OHC}$ during follow-up in both groups. Only 36 intervention group participants (38\%) continued with the program after the medical problem analysis. These participants are referred to as the "perprotocol group". In case of a medical contraindication $(\mathrm{N}=26)$, the participant continued in usual $\mathrm{OHC}$ instead. Participants whose sickness benefit had already ended or was likely to end early after randomization because recovery of workability was established $(\mathrm{N}=20)$, were by law (soon) no longer entitled to OHC by the SSA, and as such could no longer participate in the program.

Figure 1 shows how many of the per-protocol participants $(\mathrm{N}=36)$ participated in each step of the program. The figure also shows the number of participants in the intervention and control groups that had $\geq 1$ consultations with an SSA professional as well as information about referral to a vocational rehabilitation agency and medical cointerventions.

\section{Primary outcome measure}

In the intervention and control groups, 25 (27\%) and 24 (26\%) participants, respectively, returned to work sustainably during follow-up. After 327 days in the intervention group and 302 days in the control group, $\geq 25 \%$ of the participants had returned to work sustainably. The range between the minimum and maximum duration until this outcome in the intervention and control group was respectively 23-336 days and 8-321 days. Figure 2 illustrates the unadjusted Kaplan Meier curves for time until first sustainable RTW in the two groups. Table 2 presents the crude and adjusted HR. In none of the models a significant effect of allocation to the inter- vention compared to the control group was found. Also the per-protocol analysis showed no significant effect.

\section{Secondary outcome measures}

Working hours per week. Participants in the intervention and control groups who were employed during followup worked on average respectively 26.3 [standard deviation (SD) 12.6] and 25.6 (SD 14.1) hours per week, which did not differ significantly (adjusted B $-0.62,95 \%$ CI -10.83-9.59, $\mathrm{P}=0.90$ ). Also the per-protocol analysis revealed no significant differences between groups.

RTW in any type of employment. In total, 37 intervention group participants (39\%) and 40 control group participants $(43 \%)$ returned to work in paid or unpaid labor. After 181 and 167 days, $\geq 25 \%$ of the participants in the intervention and control groups, respectively, had reached this outcome. The range in duration until this outcome was 14-342 days in the intervention group and 8-348 days in the control group. Both the crude and adjusted HR are presented in table 2. Significant effect of allocation to the intervention compared to the control group was found neither in these models nor the per-protocol analysis.

Sickness benefit period. The sickness benefit ended for $45(48 \%)$ and $47(51 \%)$ participants in the intervention and control groups, respectively. After 89 days, the sickness benefit had ended for $\geq 25 \%$ of the participants in both groups, with a range of 8-336 days in the intervention group and 14-329 days in the control group. The HR for the intervention compared to control group were found to differ significantly $(\mathrm{P}<0.05)$ before and after 240 days. Table 2 presents the crude and adjusted HR for both periods and shows no significant differences between groups. Results of the per-protocol analysis differed slightly. This analysis revealed a significant delayed ending of the sickness benefit in the first 240 days for the per-protocol group in comparison with the control group (adjusted HR $0.30,95 \%$ CI $0.12-0.75$, $\mathrm{P}=0.01$ ), followed by a non-significant trend towards an earlier ending of the sickness benefit in this first group after 240 days (adjusted HR 2.79, 95\% CI 0.95-8.15, $\mathrm{P}=0.06$ ).

Health related outcomes. Table 3 summarizes the results of the (adjusted) mixed-model analyses. We found no significant differences in health outcomes between the two groups. The per-protocol analyses also revealed no significant differences between the per-protocol and control group. 


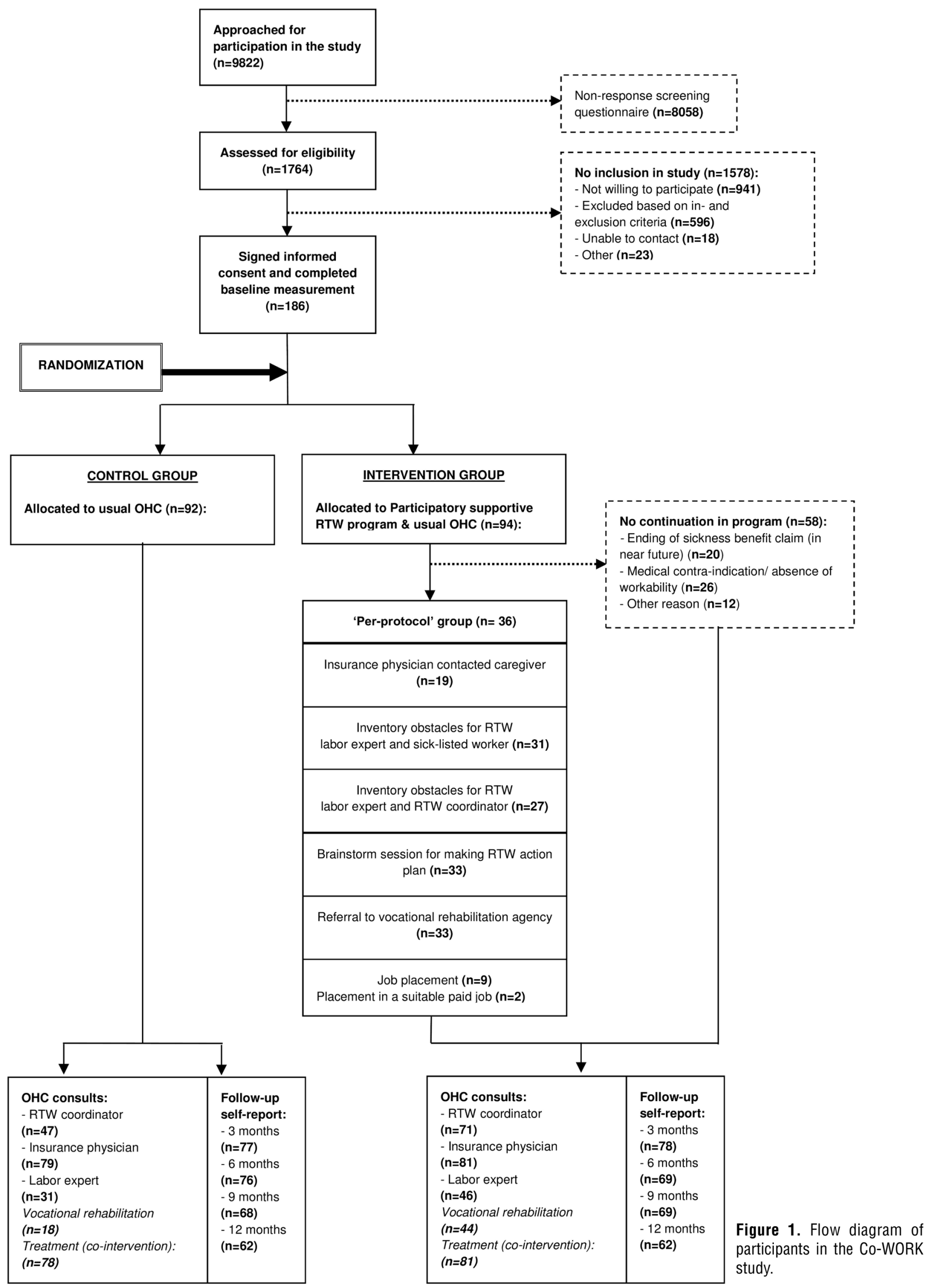


Table 1. Baseline characteristics. [ASE=attitude experienced social influence and self-efficacy regarding return to work (RTW); SF-36=36item short form health survey; $S D=$ standard deviation; $4 \mathrm{DSQ}=4$-dimensional symptom questionnaire.]

\begin{tabular}{|c|c|c|c|c|c|c|c|c|}
\hline \multirow[t]{2}{*}{ Variable } & \multicolumn{4}{|c|}{ Intervention group $(\mathrm{N}=94)$} & \multicolumn{4}{|c|}{ Control group (N=92) } \\
\hline & $\mathrm{N}$ & $\%$ & Mean & SD & $\mathrm{N}$ & $\%$ & Mean & SD \\
\hline Gender (female) & 45 & 48 & & & 47 & 51 & & \\
\hline Age (years) & & & 45.7 & 10.6 & & & 46.3 & 10.0 \\
\hline Education (low) a & 26 & 28 & & & 23 & 25 & & \\
\hline \multicolumn{9}{|l|}{ Type of worker } \\
\hline \multicolumn{9}{|l|}{ Type of worker before reporting sick } \\
\hline Unemployed & 88 & 94 & & & 85 & 92 & & \\
\hline Temporary agency & 4 & 4 & & & 2 & 2 & & \\
\hline Fixed-term contract & 2 & 2 & & & 5 & 5 & & \\
\hline Employment contract at baseline (yes) & 11 & 12 & & & 14 & 15 & & \\
\hline Work schedule in last job, day work & 72 & 77 & & & 75 & 82 & & \\
\hline Working hours per week in last job b & & & 32.6 & 11.6 & & & 31.4 & 10.8 \\
\hline Years worked in last job c & & & 10.0 & 10.0 & & & 8.7 & 9.6 \\
\hline $\begin{array}{l}\text { Expectation regarding ability for full RTW in } 6 \text { months, (very) certain } \\
\text { ASE questionnaire }{ }^{d}\end{array}$ & 4 & 4 & & & 16 & 17 & & \\
\hline Intention to RTW (yes) & 78 & 83 & & & 81 & 88 & & \\
\hline Attitude (6-30 score) & & & 15.7 & 5.2 & & & 14.9 & 4.2 \\
\hline Normative beliefs (4-20 score) & & & 12.0 & 3.1 & & & 12.6 & 2.6 \\
\hline Social modeling (2-10 score) & & & 4.8 & 1.9 & & & 4.8 & 1.5 \\
\hline Self-efficacy (2-10 score) & & & 6.3 & 1.8 & & & 6.2 & 1.6 \\
\hline Fear avoidance beliefs (4-40 score) ${ }^{\mathrm{e}}$ & & & 29.0 & 6.9 & & & 28.5 & 7.0 \\
\hline \multicolumn{9}{|l|}{$4 \mathrm{DSQ}{ }^{\dagger}$} \\
\hline Distress (0-32 score) & & & 25.8 & 5.1 & & & 26.3 & 5.4 \\
\hline Depression (0-12 score) & & & 6.7 & 3.7 & & & 6.8 & 3.9 \\
\hline Anxiety (0-24 score) & & & 10.7 & 6.1 & & & 9.8 & 6.7 \\
\hline Somatization (0-32 score) & & & 14.9 & 5.9 & & & 15.5 & 7.2 \\
\hline \multicolumn{9}{|l|}{ SF-36 g (component summary score) } \\
\hline Physical & & & 46.4 & 9.5 & & & 47.7 & 9.3 \\
\hline Mental & & & 21.0 & 8.5 & & & 22.1 & 9.1 \\
\hline
\end{tabular}

a Low educational level included no education, primary school or lower vocational education.

${ }^{b} \mathrm{~N}$ (total) is 183 due to missing cases.

${ }^{\mathrm{C}} \mathrm{N}$ (total) is 185 due to one missing case.

${ }^{\mathrm{a}}$ A lower score on these scales corresponds with a more positive attitude regarding RTW (attitude), the belief that other people think work resumption is important (normative beliefs), finding it more important what other people think (social modelling) and a stronger feeling of self-efficacy regarding RTW (self-efficacy).

${ }^{e} \mathrm{~A}$ higher score on this scale, indicates a stronger belief that health complaints could interfere with RTW.

${ }^{\dagger}$ A lower score on these scales, corresponds to fewer complaints.

${ }^{g} \mathrm{~A}$ score on these scales > standard mean of 50 corresponds to better perceived health or functioning.

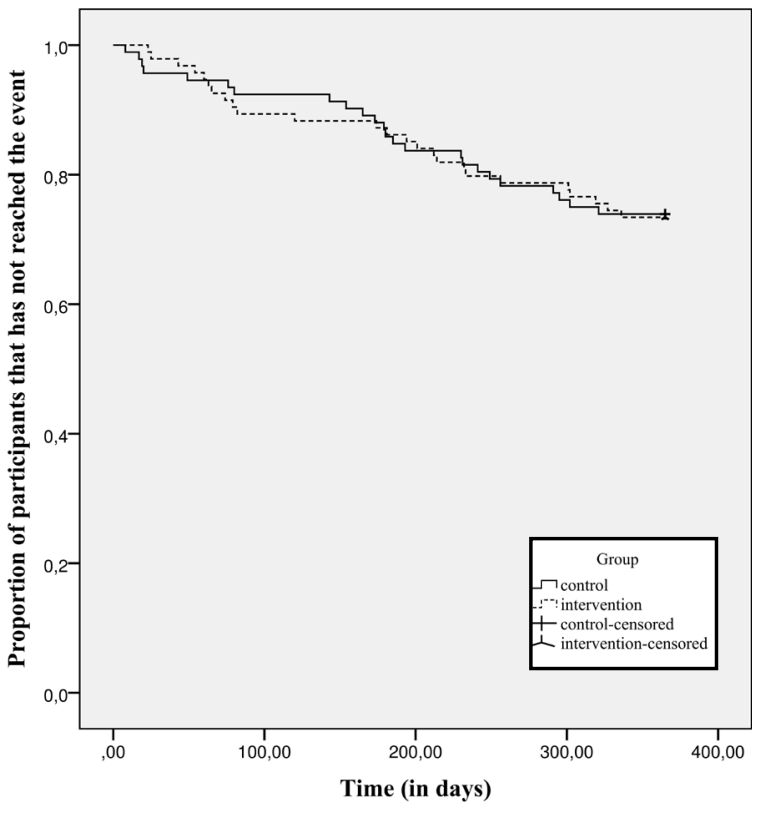

Figure 2. Kaplan Meier curves for duration until first sustainable RTW.

\section{Discussion}

\section{Main findings}

The present study showed no significant superior or adverse effect of allocation to the participatory, supportive RTW program on the duration until first sustainable RTW in comparison with usual $\mathrm{OHC}$ by the Dutch SSA. Furthermore, no significant differences were found in favor of the intervention group on any secondary outcome.

\section{Interpretation of findings}

The absence of an intervention effect on the duration until sustainable RTW could be explained by implementation failure. A very low number of intervention group participants actually participated in the RTW program $(\mathrm{N}=36)$, and even in this per-protocol group, protocol adherence was only low to moderate (27). We tried to enhance protocol adherence by a detailed 
An important consequence of the implementation failure in our study was less continuity in $\mathrm{OHC}$ than was prescribed in the protocol. Because continuity in $\mathrm{OHC}$ is considered important in enhancing RTW (40, 41), this may have influenced the effectiveness of the new program. This means that it remains unclear what the results would have been if the program had been executed according to protocol.

Nevertheless, comparing the effectiveness of a participatory RTW program across studies reveals more promising results for sick-listed workers with physical complaints compared to those with mental health problems. To illustrate, in Canada and the Netherlands, beneficial effects of a participatory RTW program on workrelated outcomes were found for sick-listed employees with low back pain (42-44) and on the duration until sustainable RTW of workers without an employment contract and sick-listed due to musculoskeletal disorders (24). Whereas, in line with our findings, no superior (overall) intervention effect on the duration until sustainable RTW was found for Dutch sick-listed employees with a CMD (12), and an adverse effect of a very similar program was found for Danish sickness absence beneficiaries with mental health problems (7). Furthermore, although we selected participants with positive RTW intentions and our analyses were adjusted for possible changes in this intention, findings were inconsistent with the beneficial intervention effect found for a similar subgroup of employees sick-listed due to a CMD with such positive intention at baseline (12). This suggests a discrepancy in findings for sick-listed workers with a CMD who still have an employment contract and those who no longer have an employment contract.

Although implementation failure will have played a role in the discrepancy in findings between our and the aforementioned studies, this discrepancy may also suggest that our RTW program has not properly addressed specific challenges in improving RTW of workers without an employment contract, sick-listed due to a CMD. One important challenge may be doubts about the sicklisted worker's readiness to return to work. Our evaluation of the program's execution in practice revealed not only that the participating professionals questioned the sick-listed workers' RTW readiness but also the sicklisted workers themselves were sometimes insecure about their capabilities (36). This feeling of insecurity may reflect an anticipated stigma or fear-avoidance beliefs, both of which have been considered important risk factors for not returning to work $(45,46)$. Another challenge was the absence of a workplace to return to. The lack of a clear RTW perspective complicated translating experienced mental health problems into concrete obstacles for RTW and finding practical solutions to overcome these obstacles (36). Furthermore, many of the participants in our study were already unemployed before reporting sick, which may have increased their distance from the labor market.

The presence of an adverse intervention effect on the sickness benefit duration, found in the per-protocol group of our present study, was also visible in Vermeulen et al's study (24), albeit not significant. In two ways, this finding can be related to SSA termination of $\mathrm{OHC}$, once the sickness benefit ends. Firstly, intervention group participants, whose sickness benefit was likely to end soon after randomization according to the insurance physician, were excluded from participation in the new program as they were soon no longer entitled to OHC. As a consequence, the per-protocol group mainly consisted of participants whose sickness benefit was unlikely to end soon. Secondly, once participation in the program had started, the insurance physicians possibly first wanted to await the effectiveness of the new program before they terminated the sickness benefit.

\section{Strengths and limitations of this study}

A strength of this study is the assessment of both first sustainable RTW in paid employment and first RTW in any type of employment, which makes it possible to compare our results with results of multiple studies on RTW interventions. Moreover, our primary outcome may be considered robust because it only includes sustainable RTW $(12,24)$. Finally, the assessment of these outcomes with the use of both registered SSA and self-reported data, minimizes possible bias caused by self-report. A first limitation of this study is that, because of its pragmatic design, generalizing our results to other settings could be difficult. A second limitation is that we may have insufficiently addressed barriers for a successful execution of the participatory, supportive RTW program before the trial began. More comprehensive intervention mapping or a pilot study prior to the trial could possibly have helped to overcome some of these barriers. A third limitation of this study is the absence of blinding of both participants and professionals for the randomization result. A last limitation is that invitations for participation in the study were sent to a very large number of sick-listed workers $(\mathrm{N}=9822)$ to be able to include the necessary number of participants in this study as it was not possible to recruit participants solely based on a registered mental health problem (27).

\section{Implications for practice and research}

Based on the results of this study, we cannot recommend to implement the RTW program in the Dutch social security sector in its current form. Firstly, it will be necessary to overcome several barriers for a successful implementation. Secondly, it may be necessary to tailor the program to the specific needs and context of workers 
without an employment contract and sick-listed due to CMD. Lessons may be learned from successful RTW interventions aimed at people with more severe mental illness, such as supported employment. Part of this approach are regular meetings between all stakeholders, including employment specialists and healthcare providers (1). This approach is a good example of how to apply an integrated care approach so that treatment and vocational needs can be addressed simultaneously. Another characteristic of supported employment is ongoing support for both the worker and his/her employer during placement in work (1). Similar support may also stimulate early and sustainable RTW of sick-listed workers with a CMD and may be an incentive for employers to hire these workers. This may help to overcome barriers resulting from a limited availability of suitable jobs. Placement in a suitable job could further be stimulated by offering subsidized workplaces, as Vermeulen et al suggested earlier (24). Future research is needed to carefully consider these suggestions for developing a more suitable RTW intervention.

\section{Concluding remarks}

Compared to usual $\mathrm{OHC}$, a participatory, supportive RTW program did not result in a significant shorter duration until sustainable RTW of workers without an employment contract and sick-listed due to a CMD. Nevertheless, due to implementation failure, it remains unclear what the results would have been if the program had been executed according to protocol. For future evaluation of a RTW program for this type of worker, it will be important to identify and overcome barriers for a successful implementation in an early phase. Further research may also be needed to consider how the vocational needs of these vulnerable workers could be better addressed.

\section{Acknowledgements}

We would like to thank all workers, Dutch SSA professionals, and the vocational rehabilitation agencies, including staff and management, for their participation. Furthermore, we would like to thank the SSA for providing us with data. We would also like to thank Dr Sylvia Vermeulen for her contributions to the trial design, development of intervention material, and general coordination of the study during the start of the trial; Dr Marijke Lammerts-Gilissen for her language revisions; Professor Dr Jos Twisk for his advice on statistical analyses; and Ms Arianne Scholten, MSc, Ms Manon Geldof, MSc, Ms Joyce Overvliet, BSc, and Ms Mirre den Ouden, MSc for their contributions to the recruit- ment of participants, data collection and data entry.

The trial was registered at the Netherlands trial register (NTR) on 7 August 2012. The registration number is NTR3563 (http://www.trialregister.nl/trialreg/admin/ retview.asp?TC=3563).

\section{Funding}

The Dutch Institute for Employee Benefit Schemes (Uitvoeringsinstituut Werknemersverzekeringen) financially supported this study.

\section{Competing interests}

Willem van Mechelen is shareholder and director of VU University Medical Center spin-off company Evalua Nederland BV (http://www.evalua.nl/) and non-executive board member of ArboUnie BV (http://www.arbounie. $\mathrm{nl} /$ ). Johannes R Anema is shareholder of VU University Medical Center spin-off company Evalua Nederland BV and holds a chair in Insurance Medicine on behalf of the Dutch Institute for Employee Benefit Schemes.

\section{References}

1. OECD. Sick on the job? Myths and Realities about Mental Health and Work, Mental Health and Work. Paris: OECD Publishing; 2012.

2. Henderson M, Glozier N, Holland Elliott K. Long term sickness absence. BMJ. 2005;330:802-3. http://dx.doi. org/10.1136/bmj.330.7495.802.

3. Lännerström L, Wallman T, Holmström IK. Losing independence--the lived experience of being long-term sick-listed. BMC Public Health. 2013;13:745. http://dx.doi. org/10.1186/1471-2458-13-745.

4. Audhoe SS, Nieuwenhuijsen K, Hoving JL, Sluiter JK, Frings-Dresen MHW. The effectiveness of the "Brainwork Intervention" in reducing sick leave for unemployed workers with psychological problems: design of a controlled clinical trial. BMC Public Health. 2015;15:377. http://dx.doi. org/10.1186/s12889-015-1728-Z.

5. Blonk RWB, Brenninkmeijer V, Lagerveld SE, Houtman ILD. Return to work: A comparison of two cognitive behavioural interventions in cases of work-related psychological complaints among the self-employed. Work and Stress. 2006;20(2):129 44. http://dx.doi.org/10.1080/02678370600856615.

6. Lander F, Friche C, Tornemand H, Andersen JH, Kirkeskov L. Can we enhance the ability to return to work among workers with stress-related disorders? BMC Public Health. 2009;9:372. http://dx.doi.org/10.1186/1471-2458-9-372.

7. Martin MHT, Nielsen MBD, Madsen IEH, Petersen SMA, Lange T, Rugulies R. Effectiveness of a coordinated and tailored return-to-work intervention for sickness absence beneficiaries with mental health problems. J Occup Rehabil. 
2013;23(4):621-30. http://dx.doi.org/10.1007/s10926-0139421-5.

8. Noordik E, Van der Klink JJ, Geskus RB, De Boer MR, Van Dijk FJH, Nieuwenhuijsen K. Effectiveness of an exposurebased return-to-work program for workers on sick leave due to common mental disorders: a cluster-randomized controlled trial. Scand J Work Environ Health. 2013;39(2):144-54. http:// dx.doi.org/10.5271/sjweh.3320.

9. Rebergen DS, Bruinvels DJ, Bezemer PD, Van der Beek AJ, Van Mechelen, W. Guideline-based care of common mental disorders by occupational physicians (CO-OP study): a randomized controlled trial. J Occup Environ Med. 2009;51(3):305-12. http://dx.doi.org/10.1097/ JOM.0b013e3181990d32.

10. Van Beurden KM, Van der Klink JJL, Brouwers EPM, Joosen MCW, Mathijssen JJP, Terluin B, et al. Effect of an intervention to enhance guideline adherence of occupational physicians on return-to-work self-efficacy in workers sicklisted with common mental disorders. BMC Public Health. 2015;15:796. http://dx.doi.org/10.1186/s12889-015-2125-3.

11. Van der Klink JJL, Blonk RWB, Schene AH, Van Dijk FJH. Reducing long term sickness absence by an activating intervention in adjustment disorders: a cluster randomised controlled design. Occup Environ Med. 2003;60(6):429-37. http://dx.doi.org/10.1136/oem.60.6.429.

12. Van Oostrom SH, Van Mechelen W, Terluin B, De Vet HCW, Knol DL, Anema JR. A workplace intervention for sick-listed employees with distress: results of a randomised controlled trial. Occup Environ Med. 2010;67(9):596-602. http://dx.doi. org/10.1136/oem.2009.050849.

13. Volker D, Zijlstra-Vlasveld MC, Anema JR, Beekman ATF, Brouwers EPM, Emons WHM, et al. Effectiveness of a blended web-based intervention on return to work for sicklisted employees with common mental disorders: results of a cluster randomized controlled trial. J Med Internet Res. 2015;17(5):e116. http://dx.doi.org/10.2196/jmir.4097.

14. Willert MV, Thulstrup AM, Bonde JP. Effects of a stress management intervention on absenteeism and return to work-results from a randomized wait-list controlled trial. Scand J Work Environ Health. 2011;37(3):186-95. http://dx.doi. org/10.5271/sjweh.3130.

15. Audhoe SS, Hoving JL, Sluiter JK, Frings-Dresen MHW. Vocational interventions for unemployed: effects on work participation and mental distress. A systematic review. J Occup Rehabil. 2010;20(1):1-13. http://dx.doi.org/10.1007/s10926009-9223-y.

16. Cornelius LR, Van der Klink JJL, Groothoff JW, Brouwer S. Prognostic factors of long term disability due to mental disorders: a systematic review. J Occup Rehabil. 2011;21(2):259-74. http://dx.doi.org/10.1007/s10926-0109261-5.

17. Ervasti J, Vahtera J, Virtanen P, Pentti J, Oksanen T, Ahola K, et al. Is temporary employment a risk factor for work disability due to depressive disorders and delayed return to work? The Finnish Public Sector Study. Scand J Work Environ Health. 2014;40(4):343-52. http://dx.doi.org/10.5271/sjweh.3424.
18. Muntaner C. Precarious employment: understanding an emerging social determinant of health. Annu Rev Public Health. 2014;35:229-53. http://dx.doi.org/10.1146/annurevpublhealth-032013-182500.

19. Berkhout E, Van den Berg E. SEO-report: Bridging the Gap: International Database on Employment and Adaptable Labour. Amsterdam: SEO Economic Research; 2010. http://www.seo. $\mathrm{nl} /$ uploads/media/bridging-the-gap-executive-summarynederlands.pdf. [Accessed 12-4-2016].

20. Kenniscentrum UWV [Knowledge Center Dutch Institute for EmployeeBenefit Schemes]. UWV Kennisverslag 2011-III [Dutch Institute for Employee Benefit Schemes Knowledge Report 2011-III]. Kenniscentrum UWV; 2011. http://www.uwv.nl/overuwv/Images/59650_UWV Kennisverslag_2011_16.11.2011_Click.pdf. [Accessed 124-2016].

21. Kenniscentrum UWV [Knowledge Center Dutch Institute for EmployeeBenefit Schemes]. UWV Kennisverslag 2016-I [Dutch Institute for Employee Benefit Schemes Knowledge Report 2016-I]. Kenniscentrum UWV; 2016. http://www.uwv. nl/overuwv/Images/UKV\%2001-2016\%20DIG\%20.pdf. [Accessed 12-4-2016].

22. Van der Burg CL, Klein Hesselink DJ, Molenaar-Cox PGM. Profilering Langdurig Zieke Vangnetters. Kenmerken en begeleiding van de vangnetpopulatie op basis van dossieronderzoek [Profiling Long Term Sick-Listed Workers without a Permanent Employment Contract. Characteristics and Guidance of Sick-Listed Workers without a Permanent Employment Contract Based on File Search]. Leiden: AStri Beleidsonderzoek en -advies [AStri Policy research and advice] 2011. http://www.uwv.nl/overuwv/Images/AStri\%20 rapport $\% 20 \mathrm{P} \% 2011 \% 20558 \% 20-\% 20$ Profilering $\% 20$ langdurig\%20zieke\%20vangnetters.pdf. Accessed 12-4-2016.

23. Versantvoort M, Van Echtelt P. Belemmerd aan het werk. Trendrapportage ziekteverzuim, arbeidsongeschiktheid en arbeidsdeelname personen met gezondheidsbeperkingen [Hindered at work. Trend report sickness absence, work disability and employment of persons with health restrictions]. Den Haag: Sociaal en Cultureel Planbureau (SCP) 2012.

24. Vermeulen SJ, Anema JR, Schellart AJM, Knol DL, Van Mechelen W, Van der Beek AJ. A participatory return-to-work intervention for temporary agency workers and unemployed workers sick-listed due to musculoskeletal disorders: results of a randomized controlled trial. J Occup Rehabil. 2011;21(3):313-24. http://dx.doi.org/10.1007/s10926-0119291-7.

25. Braam C, Van Oostrom SH, Terluin B, Vasse R, De Vet HCW, Anema JR. Validation study of a distress screener. J Occup Rehabil. 2009;19(3):231-7. http://dx.doi.org/10.1007/ s10926-009-9178-z.

26. Lammerts L, Vermeulen SJ, Schaafsma FG, Van Mechelen W, Anema JR. Return to work of workers without a permanent employment contract, sick-listed due to a common mental disorder: design of a randomised controlled trial. BMC Public Health. 2014;14:594. http://dx.doi.org/10.1186/1471-245814-594. 
27. Lammerts L, Schaafsma FG, Van Mechelen W, Anema JR. Process evaluation of a participatory supportive return to work program for workers without a permanent employment contract, sick-listed due to a common mental disorder. J Occup Rehabil. 2016 Jan 25. [Epub ahead of print]. http://dx.doi. org/10.1007/s10926-016-9625-6.

28. Terluin B, Van Marwijk HWJ, Adèr HJ, De Vet HCW, Penninx BWJH, Hermens MLM et al. The Four-Dimensional Symptom Questionnaire (4DSQ): a validation study of a multidimensional self-report questionnaire to assess distress, depression, anxiety and somatization. BMC Psychiatry. 2006;6:34. http://dx.doi.org/10.1186/1471-244X-6-34

29. Aaronson NK, Muller M, Cohen PDA, Essink-Bot M-L, Fekkes M, Sanderman R, et al. Translation, validation, and norming of the Dutch language version of the SF-36 Health Survey in community and chronic disease populations. J Clin Epidemiol. 1998;51(11):1055-68. http://dx.doi.org/10.1016/ S0895-4356(98)00097-3.

30. Ware JE Jr., Gandek B, Kosinski M,Aaronson NK, Apolone G, Brazier J, et al. The equivalence of SF-36 summary health scores estimated using standard and country-specific algorithms in 10 countries: results from the IQOLA Project. International Quality of Life Assessment. J Clin Epidemiol. 1998;51(11):1167-70. http://dx.doi.org/10.1016/S08954356(98)00108-5.

31. Audhoe SS, Hoving JL, Nieuwenhuijsen K, Friperson R, De Jong PR, Sluiter JK, et al. Prognostic Factors for the Work Participation of Sick-Listed Unemployed and Temporary Agency Workers with Psychological Problems. J Occup Rehabil. 2012;22:437-46. http://dx.doi.org/10.1007/s10926012-9358-0.

32. Lammerts L, Schaafsma F, Eikelenboom M, Vermeulen SJ, Van Mechelen W, Anema JR, et al. Longitudinal Associations Between Biopsychosocial Factors and Sustainable Return to Work of Sick-Listed Workers with a Depressive or Anxiety Disorder. J Occup Rehabil. 2015;26(1):70-9. http://dx.doi. org/10.1007/s10926-015-9588-z.

33. Van Oostrom SH, Anema JR, Terluin B, De Vet HCW, Knol DL, Van Mechelen W. Cost-effectiveness of a workplace intervention for sick-listed employees with common mental disorders: design of a randomized controlled trial. BMC Public Health. 2008;8:12. http://dx.doi.org/10.1186/1471-2458-8-12.

34. Vendrig L. De Vragenlijst Arbeidsreïntgratie [Questionnaire Work Resumption]. Diagnostiek-wijzer. 2005;8(1):27-39.

35. Vendrig L, Van Hove M, Van Meijel M, Donceel P. Voorspellen van de verwachte verzuimduur met de Vragenlijst ArbeidsReïntegratie (VAR) [Predicting the expected duration of sickness absence by using the Questionnaire Work Resumption]. TBV. 2011;19(1):7-13. http://dx.doi. org/10.1007/s12498-011-0007-x.

36 Lammerts L, Schaafsma FG, Van Mechelen W, Anema JR. Execution of a participatory supportive return to work program within the Dutch social security sector: a qualitative evaluation of stakeholders' perceptions. BMC Public Health. 2016;16:323. http://dx.doi.org/10.1186/s12889-016-2997-x.
37. Audhoe SS, Nieuwenhuijsen K, Hoving JL, Zijlstra BJ, Frings-Dresen MH, Sluiter JK. Is the "Brainwork Intervention" effective in reducing sick leave of non-permanent workers with psychological problems? Results of a controlled clinical trial. In: Dissertation S. Audhoe. Amsterdam: University of Amsterdam; 2016

38. Van Vilsteren, M, Boot CR, Voskuyl AE, Steenbeek R, Van Schaardenburg D, Anema JR. Process Evaluation of a Workplace Integrated Care Intervention for Workers with Rheumatoid Arthritis. J Occup Rehabil. 2016 ;26(3):382-91. http://dx.doi.org/10.1007/s10926-015-9624-z.

39. Anema JR, Jettinghoff K, Houtman I, Schoemaker CG, Buijs PC, van den Berg R. Medical care of employees long-term sick listed due to mental health problems: a cohort study to describe and compare the care of the occupational physician and the general practitioner. J Occup Rehabil. 2006;16:41-52. http:// dx.doi.org/10.1007/s10926-005-9001-4.

40. Nieuwenhuijsen K, Verbeek JH, Siemerink JC, TummersNijsen D. Quality of rehabilitation among workers with adjustment disorders according to practice guidelines; a retrospective cohort study. Occup Environ Med. 2003;60 Suppl 1:i21-i25. http://dx.doi.org/10.1136/oem.60.suppl_1. i21.

41. Rebergen DS, Bruinvels DJ, Bos CM, Van der Beek AJ, Van Mechelen W. Return to work and occupational physicians' management of common mental health problems--process evaluation of a randomized controlled trial. Scand J Work Environ Health. 2010;36:488-98. http://dx.doi.org/10.5271/ sjweh.3084.

42. Anema JR, Steenstra IA, Bongers PM, De Vet HCW, Knol DL, Loisel P, et al. Multidisciplinary rehabilitation for subacute low back pain: graded activity or workplace intervention or both? A randomized controlled trial. Spine (Phila $\mathrm{Pa}$ 1976). 2007;32(3):291-8. http://dx.doi.org/10.1097/01. brs.0000253604.90039.ad.

43. Lambeek LC, Van Mechelen W, Knol DL, Loisel P, Anema JR. Randomised controlled trial of integrated care to reduce disability from chronic low back pain in working and private life. BMJ. 2010;340:c1035. http://dx.doi.org/10.1136/bmj. c1035.

44. Loisel P, Abenhaim L, Durand P, Esdaile JM, Suissa S, Gosselin L, et al. A population-based, randomized clinical trial on back pain management. Spine (Phila Pa 1976 ). 1997;22(24):2911-8. http://dx.doi.org/10.1097/00007632199712150-00014.

45. Brouwers EP, Mathijssen J, Van Bortel T, Knifton L, Wahlbeck $\mathrm{K}$, Van Audenhove C, et al. Discrimination in the workplace, reported by people with major depressive disorder: a crosssectional study in 35 countries. BMJ Open. 2016;6:e09961. http://dx.doi.org/10.1136/bmjopen-2015-009961.

46. Oyeflaten I, Hysing M, Eriksen HR: Prognostic factors associated with return to work following multidisciplinary vocational rehabilitation. J Rehabil Med. 2008;40:548-54. http://dx.doi.org/10.2340/16501977-0202.

Received for publication: 19 May 2016 